\title{
Erratum to: Isolation, Characterization and Differentiation Potential of Cardiac Progenitor Cells in Adult Pigs
}

\author{
A. Vanelli • G. Pennarossa • S. Maffei • B. G. Galvez • \\ G. Cossu • M. Rahaman • F. Gandolfi • T. A. L. Brevini
}

Published online: 13 March 2012

(C) Springer Science+Business Media, LLC 2012

\section{Erratum to: Stem Cell Rev and Rep}

DOI 10.1007/s12015-011-9339-2

As published, the authors are listed as A. Vanelli, G. Pennarossa, S. Maffei, G. B. Galvez, G. Cossu, M. Rahaman, F. Gandolfi, and T. A. L. Brevini.

The authors should be listed as A. Vanelli, G. Pennarossa, S. Maffei, B. G. Galvez, G. Cossu, M. Rahaman, F. Gandolfi, and T. A. L. Brevini as shown above.

The online version of the original article can be found at http://dx.doi. org/10.1007/s12015-011-9339-2.

A. Vanelli $\cdot$ G. Pennarossa $\cdot$ S. Maffei $\cdot$ M. Rahaman •

F. Gandolfi · T. A. L. Brevini $(\square)$

Unistem, Laboratory of Biomedical Embryology,

Università degli Studi di Milano,

via Celoria 10,

Milan, Italy

e-mail: tiziana.brevini@unimi.it

B. G. Galvez

Centro Nacional de Investigaciones Cardiovasculares (CNIC),

Madrid, Spain

G. Cossu

Stem Cell Research Institute, San Raffaele Hospital,

Milan, Italy 